\title{
Role of Vitamin D in Vascular calcification
}

\author{
*Dr. Abdulrazzaq Alobaid ${ }^{1}$ and Dr. Abdul Nasser Al Othman ${ }^{2}$ \\ Kuwait Institute of Medical Specialization, Kuwait
}

Submission: February 21, 2017; Published: March 06, 2017

*Corresponding author: Abdulrazzaq Alobaid, Kuwait Institute of Medical Specialization, P.0. Box: 1160 Surra 45712, Kuwait, Tel: (+965) 99610013; Email: dralobaid@hotmail.com

Abstract

The role of vitamin $\mathrm{D}$ and its derivatives in vascular calcification is complex. It has long been known that in humans, hypervitaminosis D may be associated with extensive arterial calcium phosphate deposits, mostly in the form of apatite crystals.

Keywords: Vitamin D; Vascular Calcification; Hypervitaminosis D

\section{Introduction}

In experimental animals, the administration of pharmacological doses of vitamin D sterols can lead to widespread arterial calcification, especially in association with favorable conditions such as atherosclerosis, diabetes and chronic kidney disease (CKD) [1-5].

The mechanisms by which high doses of vitamin D or its derivatives induce vascular calcification include an increase in serum calcium and phosphate, the formation of fetuin-A mineral complexes in association with a decrease in free serum levels of fetuin-A [6] and the local induction of osteochondrogenic programs with transformation of vascular smooth muscle cells (VSMCs) into osteoblast-like cells [7].

In adult patients with CKD, both before [8] and after the initiation of dialysis therapy [9], the severity and progression of vascular calcification have been found by two groups to correlate with circulating 25-hydroxyvitamin D [25(OH)D] levels. However, another group failed to identify an independent association of arterial calcification with serum 25(OH) D and 1,25-dihydroxyvitamin D [1,25(diOH) D] concentrations although both of them were negatively correlated with aortic pulse wave velocity and positively with brachial artery distensibility and flow-mediated dilatation [10]. Barreto et al. [11] also did not find an association between serum 25(OH) D levels and aortic calcification or stiffness in patients with different stages of CKD [11].

The long-term administration of vitamin D sterols to children and young adults with CKD was found to induce vascular calcification $[12,13]$. The prevalence of calcinosis was higher in the children treated with calcitriol than in those treated with vitamin D2 or vitamin D3 [13]. Of note, different types of active vitamin $\mathrm{D}$ derivatives, when given in high amounts to animals with CKD, are not endowed with the same calcification-inducing capacity.

Available data indicate that vitamin D exerts a biphasic 'dose response' curve on vascular calcification with deleterious consequences not only of vitamin D excess but also of vitamin D deficiency [14]. Karol E. Watson et al. [15] undertook the current investigation to determine the role of systemic osteoregulatory factors on development of vascular calcification. The surprising finding of these studies is that lower serum 1, 25-vitamin D levels, which have been shown by other investigators to be associated with lower levels of bone calcification, [15] are associated with higher levels of vascular calcification [16].

Mizobuchi et al. [17] suggest that experimental and clinical researches have revealed that both vitamin D excess and vitamin D deficiency have been shown to be associated with vascular calcification in uremic milieu. On the other hand, although there are some biases, recent large observational studies have demonstrated that vitamin $\mathrm{D}$ has beneficial effects on the mortality of patients with CKD independent of serum Ca, P, and parathyroid hormone levels, likely due to its activation of the vitamin D receptor in vasculature and cardiac myocytes [17].

The relationships of vitamin D with atherosclerotic calcification and with aortic medial calcification are strong and most likely involve multiple mechanisms within the complex, bone-vascular-renal endocrine axis. Nevertheless, clinical studies also indicate that there is a narrow range of vitamin D levels within which vascular function is optimized and levels above or below this range seem to confer increased risk for cardiovascular disease [18]. 
Atdosagessufficient to correctsecondaryhyperparathyroidism, calcitriol and paricalcitol were protective against aortic calcification, but higher dosages stimulated aortic calcification. They concluded that low, clinically relevant dosages of calcitriol and paricalcitol may protect against CKD-stimulated vascular calcification [19].

Harvey et al. [20] concluded that (1) calcium and vitamin D supplementation leads to a modest reduction in fracture risk, although population-level intervention has not been shown to be an effective public health strategy; (2) supplementation with calcium alone for fracture reduction is not supported by the literature; (3) side effects of calcium supplementation include renal stones and gastrointestinal symptoms; (4) vitamin D supplementation, rather than calcium supplementation, may reduce falls risk; and (5) assertions of increased cardiovascular risk consequent to calcium supplementation are not convincingly supported by current evidence. In conclusion, they recommend, on the basis of the current evidence, that calcium supplementation, with concomitant vitamin D supplementation, is supported for patients at high risk of calcium and vitamin $\mathrm{D}$ insufficiency, and in those who are receiving treatment for osteoporosis [20].

Palermo et al. [21] Vitamin $\mathrm{K}$ is in fact required for osteocalcin carboxylation that in turn regulates bone mineral accretion; it seems to promote the transition of osteoblasts to osteocytes and also limits the process of osteoclastogenesis. Several observational and interventional studies have examined the relationship between vitamin $\mathrm{K}$ and bone metabolism, but findings are conflicting and unclear [21].

It has been suggested that vitamin D and vitamin K may have a synergistic action, but it is not currently known if it occurs in an independent manner.

\section{Conclusion}

Deficient calcitriol concentrations probably contribute to the massive vascular calcification seen in chronic kidney disease. In patients with end-stage renal disease and end-stage heart failure, very low-circulating calcitriol levels or nonuse of active vitamin D or both are independently associated with high mortality rates. The effects of vitamin D on vascular calcification are complex and highly dependent upon the dose being administered. Whether the effects of vitamin D are beneficial or toxic falls within a narrow range of vitamin D levels.

\section{References}

1. Bas A, LopezI, Perez J, Rodriguez M, Aguilera-Tejero E (2006) Reversibility of calcitriol-induced medial artery calcification in rats with intact renal function. J Bone Miner Res 21(3): 484-490.

2. Al-Aly Z, Shao JS, Lai CF, Huang E, Cai J, et al. (2007) Aortic Msx2-Wnt calcification cascade is regulated by TNF-alpha-dependent signals in diabetic Ldlr-/- mice. Arterioscler Thromb Vasc Biol 27(12): 25892596.

3. Lopez I, Mendoza FJ, Aguilera Tejero E, J Perez, F Guerrero, et al. (2008) The effect of calcitriol, paricalcitol, and a calcimimetic on extraosseous calcifications in uremic rats. Kidney Int 73(3): 300-307.
4. Mathew S, Lund RJ, Chaudhary LR, Geurs T, Hruska KA (2008) Vitamin D receptor activators can protect against vascular calcification. J Am Soc Nephrol 19(8): 1509-1519.

5. Ivanovski O, Nikolov IG, Joki N, Caudrillier A, Phan O, et al. (2009) The calcimimetic R-568 retards uremia-enhanced vascular calcification and atherosclerosis in apolipoprotein E deficient (apoE-/-) mice. Atherosclerosis 205(1): 55-62.

6. Price PA, Williamson MK, Nguyen TM, Than TN (2004) Serum levels of the fetuin-mineral complex correlate with artery calcification in the rat. J Biol Chem 279(3): 1594-1600.

7. Zebger Gong H, Muller D, Diercke M, Haffner D, Hocher B, et al. (2011) 1,25-Dihydroxyvitamin D-3-induced aortic calcifications in experimental uremia: up-regulation of osteoblast markers, calciumtransporting proteins and osterix. J Hypertens 29(2): 339-348.

8. Garcia-Canton C, Bosch E, Ramirez A, Gonzalez Y, Auyanet I, et al (2011) Vascular calcification and 25-hydroxyvitamin D levels in nondialysis patients with chronic kidney disease stages 4 and 5. Nephrol Dial Transplant 26(7): 2250-2256.

9. Goldsmith DJ, Covic A, Sambrook PA, Ackrill P (1997) Vascular calcification in long-term haemodialysis patients in a single unit: a retrospective analysis. Nephron 77(1): 37-43.

10. London GM, Guerin AP, Verbeke FH, Pannier B, Boutouyrie P, et al. (2007) Mineral metabolism and arterial functions in end-stage renal disease: potential role of 25-hydroxyvitamin D deficiency. J Am Soc Nephrol 18(2): 613-620.

11. Barreto DV, Barreto FC, Liabeuf S, Temmar M, Boitte F, et al. (2009) Vitamin D affects survival independently of vascular calcification in chronic kidney disease. Clin J Am Soc Nephrol 4(6): 1128-1135.

12. Briese S, Wiesner S, Will JC, Lembcke A, Opgen-Rhein B, et al. (2006) Arterial and cardiac disease in young adults with childhood-onset endstage renal disease-impact of calcium and vitamin D therapy. Nephrol Dial Transplant 21(7): 1906-1914.

13. Milliner DS, Zinsmeister AR, Lieberman E, Landing B (1990) Soft tissue calcification in pediatric patients with end-stage renal disease. Kidney Int 38(5): 931-936.

14. Zittermann A, Schleithoff SS, Koerfer R (2007) Vitamin D and vascular calcification. Curr Opin Lipidol 18(1): 41-46.

15. Civitelli R (1995) The role of vitamin D metabolites in the treatment of osteoporosis. Calcif Tissue Int 57(6): 409-414.

16. Watson KE, Abrolat ML, Malone LL, Hoeg JM, Doherty T, et al. (1997) Active Serum Vitamin D Levels Are Inversely Correlated With Coronary Calcification. Circulation 96(6): 1755-1760.

17. Rodriguez M, Martinez-Moreno JM, Rodríguez-Ortiz ME, MuñozCastañeda JR, Almaden Y (2011) Vitamin D and vascular calcification in chronic kidney disease. Kidney Blood Press Res 34(4): 261-268.

18. Hsu JJ, Tintut Y, Demer LL (2008) Vitamin D and Osteogenic Differentiation in the Artery Wall. Clin J Am Soc Nephrol 3(5): 15421547.

19. Mathew S, Lund RJ, Chaudhary LR, Geurs T, Hruska KA (2008) Vitamin D Receptor Activators Can Protect against Vascular Calcification. J Am Soc Nephrol 19(8): 1509-1519.

20. Harvey NC, Biver E, Kaufman JM, Bauer J, Branco J, et al. (2017) The role of calcium supplementation in healthy musculoskeletal ageing : An expert consensus meeting of the European Society for Clinical and Economic Aspects of Osteoporosis, Osteoarthritis and Musculoskeletal Diseases (ESCEO) and the International Foundation for Osteoporosis (IOF). Osteoporos Int 28(2): 447-462.

21. Andrea Palermo, Dario Tuccinardi, Luca D’Onofrio, Mikiko Watanabe, Daria Maggi (2017) Vitamin K and Osteoporosis: Myth or Reality? Metabol 70: 57-71. 
This work is licensed under Creative Commons Attribution 4.0 License DOI: $10.19080 /$ OROAJ.2017.05.555654
- Quality Editorial service

- Swift Peer Review

- Reprints availability

- E-prints Service

- Manuscript Podcast for convenient understanding

- Global attainment for your research

- Manuscript accessibility in different formats

( Pdf, E-pub, Full Text, Audio)

- Unceasing customer service

Track the below URL for one-step submission https://juniperpublishers.com/online-submission.php 